\title{
PENGARUH PENAMBAHAN LATIHAN CORE STABILITY TERHADAP PENINGKATAN KESEIMBANGAN BERDIRI PADA PENDERITA STROKE DI KECAMATAN MEDAN TUNTUNGAN
}

\author{
Harrijun Kapabella Siregarl, Tinah $^{2}$ \\ Politeknik Kesehatan Kementerian Kesehatan Medan ${ }^{12}$ \\ harry_bobath@yahoo.co.id ${ }^{l}$
}

\begin{abstract}
Patients with stroke will experience various balance disorders. Standing balance disorders in stroke patients are related to the inability to regulate weight transfer and decreased muscle mobility so that body balance decreases. Patients with recurrent strokes have problems with postural control, thus hindering their movement. Balance is also a parameter for stroke patients to the success of their therapy, so that the functional ability of stroke survivors will suffer a lot. A good intervention by providing activation of the core muscles in the form of Core Stability exercises is expected to be able to increase the strength of the core muscles that are able to support the body to stay strong.

This study aims to determine the effect of core stability with improved standing balance in stroke patients in Medan Tuntung District. The treatment was carried out at the Physioroom Clinic in Medan. The type of research used is a quasi experiment using a pre test and post test group design. The study was conducted on 20 stroke patients who were given Core Stability exercises before and after the intervention. The statistical test used was paired t-test.

The results showed that the mean value of pre 53.40 and the mean of post was 43.75. The results of the analysis using the paired t-test obtained the value of $p=0.000$ where $p<0.001$. So the results obtained there is an effect of core stability training on improving standing balance in stroke patients in the Medan fortune district.
\end{abstract}

Keywords: Patients with poststroke, Intervention core stability, improved standing balance.

\begin{abstract}
ABSTRAK
Pasien dengan stroke akan mengalami berbagai gangguan keseimbangan. Gangguan keseimbangan berdiri pada pasien stroke berhubungan dengan ketidakmampuan untuk mengatur perpindahan berat badan dan kemampuan gerak otot yang menurun sehingga kesetimbangan tubuh menurun. Pasien dengan stroke berulang memiliki masalah dengan kontrol postural, sehingga menghambat gerakan mereka. Keseimbangan juga merupakan parameter bagi pasien stroke terhadap keberhasilan terapi mereka.sehingga kemampuan fungsional penderita stroke akan banyak mengalami gangguan. Intervensi yang baik dengan memberikan aktivasi otot-otot core muscle berupa latihan Core Stability diharapkan akan mampu meningkatkan kekuatan otot-otot core muscle yang mampu menopang bantang tubuh agar tetap kuat.

Penelitian ini bertujuan untuk mengetahui pengaruh core stability dengan perbaikan keseimbangan berdiri pada penderita stroke di Kecamatan Medan Tuntungan dengan perlakuan dilakukan di Klinik Physioroom Medan. Jenis penelitian yang digunakan yaitu quasi eksperiment dengan menggunakan rancangan pre test dan post test group. Penelitian dilakukan terhadap 20 penderita stroke dengan diberikan latihan Core Stability sebelum dan sesudah intervensi. Uji statistic yang digunakan adalah paired t-test.

Hasil penelitian menunjukkan nilai rerata pre 53,40 dan rerata post 43,75. Hasil analisis menggunakan paired t-test diperoleh nilai $p=0,000$ dimana $p<0,001$. Maka hasil yang didapat ada pengaruh Latihan core stability terhadap peningkatan keseimbangan berdiri pada penderita stroke di kecamatan medan tuntungan.

Kata kunci: pasien dengan post stroke, Inetrvensi core stability, peningkatan keseimbangan berdiri.
\end{abstract}

Latar Belakang

Pasien dengan Stroke akan mengalami banyak gangguan-gangguan yang bersifat fungsional. Gejala stroke dapat bersifat fisik, psikologis, dan atau perilaku. Gejala fisik paling 
sensasi pada wajah, lengan atau tungkai dike duduk. Pasien-pasien yang mengalami gangguan salah satu sisi tubuh, kesulitan bicara dan atausensasi posisi tubuh akan cenderung ke arah vertikal. memahami (tanpa gangguan pendengaran), kesulitan menelan dan hilangnya sebagian penglihatan di satu sisi.

Kelemahan ektremitas sesisi, kontrol tubuh yang buruk serta ketidak stabilan pola berjalan merupakan aspek-aspek pada pasien stroke yang tidak terpisahkan. Kelemahan dari lengan, kedua tungkai, kelemahan sebagian otot-otot wajah merupakan hal umum yang terjadi pada pasien stroke.

Pasien dengan stroke juga akan mengalami berbagai gangguan keseimbangan. Gangguan keseimbangan berdiri pada pasien stroke berhubungan dengan ketidakmampuan untuk mengatur perpindahan berat badan dan kemampuan gerak otot yang menurun sehingga kesetimbangan tubuh menurun. Pasien dengan stroke berulang memiliki masalah dengan kontrol postural, sehingga menghambat gerakan mereka. Keseimbangan juga merupakan parameter bagi pasien stroke terhadap keberhasilan terapi mereka.

Pada pasien stroke, mereka berusaha membentuk gerakan kompensasi untuk gangguan kontrol postur mereka, kompensasi ini tidak selalu menjadi hasil yang optimal. Pasien dengan gangguan keseimbangan yang moderat hingga berat menggunakan banyak gerakan tambahan sebagai kompensasi dari defisit motoriknya, sedangkan untuk pasien dengan gangguan keseimbangan yang ringan, mereka memiliki kemampuan melakukan gerakan yang hampir sama dengan pola gerak normal.

Gangguan fungsi keseimbangan terutama saat berdiri tegak, merupakan akibat stroke yang paling berpengaruh pada faktor aktivitas sejak kemampuan keseimbangan tubuh dibidang tumpu mengalami gangguan dalam beradaptasi terhadap gerakan dan kondisi lingkungan.

Gangguan sensoris dan motorik post stroke mengakibatkan gangguan keseimbangan termasuk kelemahan otot, penurunan fleksibilitas jaringan lunak, serta gangguan kontrol motorik dan sensorik. Fungsi yang hilang akibat gangguan kontrol motorik pada pasien stroke mengakibatkan hilangnya koordinasi, hilangnya kemampuan merasakan keseimbangan tubuh dan postur (kemampuan untuk mempertahankan posisi tertentu). Kesulitan membentuk dan mempertahankan postur yang tepat dapat diketahui saat pasien melakukan gerakan ke berdiri maupun Tujuan Penelitian

Tujuan dari penelitian ini adalah untuk mengetahui pengaruh pemberian Latihan core

Penurunan fungsi otot pada ekstremitas bawah mengakibatkan penurunan kemampuan untuk menyanggah, menahan dan menyeimbangkan massa tubuh. Selain itu terjadi kesulitan untuk memulai, mengarahkan, mengukur kecepatan kemampuan otot untuk mempertahankan keseimbangan tubuh. Keterlambatan untuk aktivitas otot dan melambatnya pembentukan gerakan memperngaruhi stabilitas serta respon kecepatan keseimbangan tubuh. Karena hal tersebut diatas menyebabkan banyak dari pasien stroke mengalami penurunan kemampuan hingga terjatuh saat mulai gerakan berdiri dan berjalan.

Perubahan adaptasi otot tubuh berupa penurunan kemampuan panjang otot dan kekakuan mempengaruhi kontraksi otot dan keseimbangan. Penurunan elastisitas jaringan lunak dan pemendekan otot membatasi mobilitas sendi di pergelangan kaki mempengaruhi pasien stroke geriatri (Vandervoort, 1999).

Kemampuan memberikan latihan yang meningkatkan aktivitas proprioceptive dan cutaneus pada telapak kaki akan sangat membantu meningkatkan keseimbangan insan stroke. Hal ini dikarenakan kita (manusia) adalah mahluk bipedal atau berdiri dengan dua kaki.

Otak merupakan jaringan atau organ tubuh yang sangat vital keberadaan serte f.......... tapat terganggu oleh suatu serangan cara tiba-tiba dan mendadak, serta _._. _atan terlebih dahulu yang sering di sebut dengan stroke.

Stroke menduduki urutan ketiga penyebab kematian setelah penyakit jantung dan kanker. Stroke masih merupakan penyebab utama dari kecacatan. Data dari NHLB's Farming Hert Study. Di Indonesia belum ada data epidemiologi stroke yang lengkap, tetapi proporsi penderita stroke dari tahun ke tahun cenderung meningkat. Hal ini terlihat dari laporan survey kesehatan rumah tangga Depkes RI di berbagai Rumah Sakit di 27 provinsi di Indonesia. Hasil survey itu menunjukan terjadinya peningkatan antara 1984 sampai 1986, dari 0,72 per 100 penderita pada 1984 menjadi 0,89 per 100 penderita pada 1986 . (Tjipto Hariyono, 2008).

stability terhadap peningkatan keseimbangan berdiri pada post stroke

\section{Hipotesis (Opsional)}


Ada pengaruh pemberian latihan Core Stability terhadap peningkatan keseimbangan berdiri pada post stroke

\section{METODE}

Penelitian ini merupakan Preeksperimental dengan menggunakan rancangan penelitian one group pre test - post test design (Notoadmojo, 2002), dengan tujuan untuk mengetahui secara langsung efek Core Stability terhadap peningkatan keseimbangan berdiri pada penderita post stroke hemiparese sebelum perlakuan dengan sesudah perlakuan pada satu kelompok.

Pada kelompok perlakuan, diberikan intervensi exercise core stability. Sebelum perlakuan dilakukan pengukuran dengan Berg Balance Scale untuk menilai keseimbangan berdiri pada penderita post stroke hemiparese fase recovery. Setelah perlakuan, kembali diukur keseimbangan berdirinya dengan Berg Balance Scale untuk melihat dampak dari perlakuan tersebut.

Adapun bentuk rancangan penelitian ini dapat di gambarkan dengan pola sebagai berikut :

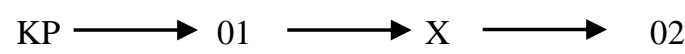

Gambar 3.1. Model rancangan penelitian One group pre test-post test design.

Keterangan :

KP = Kelompok Perlakuan

$\mathbf{O}_{1} \quad=$ Pengamatan pertama

$\mathbf{X} \quad=$ Intervensi

$\mathbf{O}_{2} \quad=$ Pengamatan kedua

\section{HASIL}

\section{Deskripsi Sample}

Penelitian ini dilakukan pada 20 Sample yaitu pasien dengan diagnosa post stroke hemiparese fase recovery di Klinik Physioroom yang dipilih secara keseluruhan (total sampling) berusia antara 40 - 70 tahun. Dari hasil penelitian dapat dideskripsikan seperti berikut:

\section{Tabel 1}

sebagian besar berpersepsi baik sebanyak 12 Orang $(60 \%)$, kemudian berpersepsi cukup sebanyak 4 orang $(20 \%)$, dan tingkat berpersepsi kurang sebanyak 4 orang $(20 \%)$.
Deskripsi Subjek Penelitian Berdasarkan Jenis Kelamin Pada Perlakuan Core Stability

$\begin{array}{llll}\text { No } & \text { Jenis } & \text { Frekuens } & \text { Persentas } \\ & \text { Kelami } & \text { i } & \text { e }(\%)\end{array}$

$\mathrm{n}$

$\begin{array}{llll}1 . & \text { Laki- } & 12 & 60 \\ 2 & \text { laki } & 8 & 40 \\ & \text { Peremp } & & \\ & \text { uan } & & \\ & \text { Jml } & \mathbf{2 0} & \mathbf{1 0 0}\end{array}$

Berdasarkan tabel di atas tampak bahwa subjek di klinik Physioroom sebagian besar adalah berjenis kelamin laki-laki yaitu sebanyak 12 orang (60\%), dan sebagian kecil berjenis kelamin perempuan yaitu sebanyak 8 orang $(40 \%)$.

Tabel 2

Deskripsi Sample Penelitian Berdasar Penggolongan Usia Pada Perlakuan Core Stability No Usia Frekuensi Persentase

$\begin{array}{llll}\text { 1. } & 40-50 & 2 & (\%) \\ \text { 2. } & \text { tahun } & 8 & 10 \\ \text { 3. } & 51-60 & 10 & 40 \\ & & \end{array}$

tahun

$61-70$

tahun

Jumlah $10 \quad 100$

Berdasarkan tabel di atas tampak bahwa sebagian besar subjek penelitian di klinik Physioroom adalah usia 61 - 70 tahun yaitu sebanyak 10 orang (50\%), kemudian usia $51-60$ tahun sebanyak 8 orang $(40 \%)$, dan yang berusia $40-50$ tahun 2 orang $(10 \%)$.

Tabel 3

Deskripsi Subjek Penelitian Berdasar Tingkat Persepsi Pada

Perlakuan Core Stability

No Persepsi Frekuensi Persentase

$\begin{array}{llll}\text { 1. } & \text { Baik } & 12 & (\%) \\ \text { 2. } & \text { Cukup } & 4 & 60 \\ \text { 3. } & \text { Kurang } & 4 & 20 \\ & \text { Jumlah } & \mathbf{2 0} & \mathbf{1 0 0}\end{array}$

Berdasarkan tabel di atas tampak bahwa sebagian besar subjek penelitian di Klinik Physioroom

Tabel 4

Data Tingkat Keseimbangan Subjek Penelitian Pada

Kelompok Perlakuan Core Stability 

Vol. 15 No. 3 September - Desember 2020

$\begin{array}{llll}\text { No } & \text { Subjek } & \text { Frekuensi } & \begin{array}{l}\text { Persentase } \\ (\%)\end{array} \\ \text { 1. } & >45 & 4 & 20 \\ \text { 2. } & 46-54 & 9 & 45 \\ \text { 3. } & 55-56 & 7 & 35 \\ & \text { Jml } & \mathbf{2 0} & \mathbf{1 0 0}\end{array}$

Berdasarkan tabel di atas tampak bahwa sebagian besar subjek penelitian di Klinik Physioroom sebagian besar adalah dengan tingkat keseimbangan yang rendah yaitu sebanyak 4 orang (20\%), dan dengan tingkat keseimbangan sedang skor 45-54 sebanyak 9 orang (45\%), dan tingkat keseimbangan yang tinggi dengan skor 54-56 sebanyak 7 orang $(35 \%)$.

Tabel 5

Data Perbedaan Rata-rata nilai Keseimbangan Subjek Penelitian Pada

Kelompok Perlakuan pre dan post Core Stability

\begin{tabular}{lccc}
\hline $\begin{array}{l}\text { Core } \\
\text { tability }\end{array}$ & Mean & $t$ & $P$ \\
\hline $\begin{array}{l}\text { Pre } \\
\text { test }\end{array}$ & 53,40 & 12,553 & 0,000 \\
Post & & & \\
test & 43,75 & &
\end{tabular}

Berdasarkan tabel di atas gambaran pre test dan post test penelitian di Klinik Physioroom sebagian besar adalah dengan skor sebelum diberikan latihan core stability sebesar 53,40 dan skor setelah diberikan latihan core stability sebesar 43,75, terlihat menunjukkan hasil yang berpengaruh pemberian latihan core stability pada penderita stroke untuk meningkatkan keseimbangan

\section{PEMBAHASAN}

Pengaruh Latihan Core Stability Terhadap Peningkatan Keseimbangan Berdiri Pada Stroke. Penelitian ini bertujuan untuk melihat pengaruh latihan core stability terhadap peningkatan keseimbangan berdiri pada post stroke.

Hasil analisis data menunjukkan adanya pengaruh core stability terhadap peningkatan keseimbangan berdiri pada post stroke. Uji hipotesis pada responden latihan core stability pada penelitian ini di temukan bahwa nilai signifikan $=0,001$ yang berarti nilai $0,001<0,05$, dari hasil uji hipotesis ini menunjukan bahwa latihan core stability mempunyai pengaruh secara signifikan terhadap tingkat keseimbangan berdiri pada pasien stroke hemiparese.

1. Uji hipotesis core stability pada penelitian ini di temukan bahwa nilai signifikan = 0,02 yang berarti nilai $0,02<0,05$, dari hasil uji hipotesis ini menunjukan bahwa latihan core stability mempunyai pengaruh secara signifikan terhadap tingkat keseimbangan berdiri pada pasien stroke.

Hasil penelitian ini sesuai dengan pendapat yang dikemukakan Menurut Penelitian Nicole Kahle dari The University of Toledo pada April 2009, Keseimbangan dinamis adalah komponen kunci dari kegiatan normal sehari-hari seperti berjalan, berlari dan memanjat tangga. Karena keseimbangan merupakan aspek penting dari kehidupan sehari-hari, sangat penting untuk menemukan program yang berguna untuk menjaga keseimbangan yang tepat. Satu saran seperti yang telah dilakukan dalam upaya untuk meningkatkan keseimbangan adalah korelasi antara pelatihan kekuatan otot dan keseimbangan ditingkatkan. Latihan utama core muscles telah didapatkan sebagai program perbaikan, tapi ada kurangnya bukti ilmiah saat ini untuk mendukung klaim ini. Penyelidikan lebih lanjut pada program core stability mempunyai efek pada keseimbangan, oleh karena itu diperlukan dalam upaya untuk memberikan program pemeliharaan keseimbangan.

\section{KESIMPULAN}

Berdasarkan hasil penelitian yang telah dipaparkan dalam bab sebelumnya, maka kesimpulan yang dapat di ambil adalah sebagai berikut :

Ada pengaruh pemberian latihan core stability terhadap peningkatan keseimbangan berdiri pada post stroke. Selanjutnya berdasarkan hasil penelitian ini peneliti memiliki rencana untuk tahapan berikutnya dengan melakukan Pengabdian Masyarakat sehingga dapat dirasakan langsung oleh masyarakat insane stroke dan keluarga. Dimana saat pelaksanaan Pengabdian masyarakat nanti pihak keluarga, pendamping insane stroke akan peneliti berikan edukasi agar dapat melakukan tekhnik core stability terhadap keluarganya.

\section{DAFTAR PUSTAKA}

1. Arif W, 2008. Pengaruh pemberian PNF terhadap kekuatan fungsi prehension pada pasien stroke hemoragic dan non hemoragic. Jurnal Fisioterapi Indonusa, ISSN: 1858-4047 Vol. 8 No. 1 April 2008 hal 83 - 108 . 
2. Bruno, 2004. Motor recovery in stroke, (cited 2004 Dec 9) available from: URL:

3. http:/www.medicine.com.

4. Bohannon, R. 2001 Gait After Stroke. Orthopedic Physical Therapy Clinics of America, hal $151-170$

5. Bohannon, R.W. 1993 Ordinal and Timed Balance Measurement : Realibility and Validity in Patients with Stroke. Clinical rehabilitation

6. Budiarto Eko, 2003, Biostatistika, untuk kedokteran dan kesehatan masyarakat, Jakarta : EGC

7. Carr, JH, Shepherd, RB. 2004. Stroke Rehabilitation, guideliness for exercise \& training optimize motor skills. UK : Butterworth Heinemann.

8. Daniel, Wayne W, 1995, Biostatistics, A Foundation for Analysis in the Health Sciences, New York : John wiley \& Sons, inc

9. De Haan R, Horn J, Limburg M. A comparison of five stroke scales with measures of

disability, handicap, and quality of life. Stroke 1993; 24: 1178-1881.

10. Domholdt E, 2000. Physical Therapy Research, Principles and Applications, $2^{\text {nd }}$ Edition, London :WB Saunders Company

11. Duvernoy HM, 2005. The Human Hippocampus, Functional Anatomy, Vascularization, Third Edition. NY : SpringerVerlag Berlin Heidelberg.

12. Feigin, 2006. Stroke. Jakarta : Bhuana Ilmu Populer.

13. Gallahue, D. L. 1998. Understanding Motor Development. USA: McGraw Hill companies.

14. Ganong, W.F. 2003. Fisiologi Kedokteran. Ed.20. Jakarta : EGC.

15. Gilroy J, 2000. Basic Neurology. 3th New York : Mc Graw Hill, p . 226 , 275 - 9

16. Goodman C, and Boissonnault, G.W. 1998. Pathology : Implication for the physical therapist. Philadelphia: W.B. Sounders Company.

17. Hendelman, W. 2006. Atlas of Functional Neuroanatomy.2Sc. Ed. Boca Raton : CRC Press.

18. Hiks, Carolyn M, 1995 , Reseach for Physiotherapists, Project Design and Analysis, USA : Churchill Livingstone.

19. Irfan, M. 2010. Fisioterapi Bagi Insan Stroke. Yogyakarta : Graha Ilmu.

20. Kisner, Carolyn and Colby, Lynn Allen. 1996. Therapeutic Exercise Foundations and
Techniques, Third Edition. Philladelphia: FA Davis company.

21. Leonard, Charles T. 1998. The Neuroscience of Human Movement. USA : Mosby.

22. Magoun, HW. 2005. American Neuroscience in The Twentieth Century. Tokyo: AA Balkema Publisher.

23. Marlow, C. 2008. Stroke Practical Management. 3th. Ed. UK: Blackwell Publishing.

24. Misbach J. Stroke, Aspek diagnostik, patofisiologi, manajemen. Jakarta: Balai Penerbit

25. FKUI 1999.p. 1-8, 55-6.

26. Noback RC, Strominger LN, Demares RJ, Ruggeiro DA, 2005. The Human Nervous System, Sixth Edition, NY : Humana Press

27. Noerjanto M. Management of acute stroke. In: Sotedjo, ed. Masalah-masalah dalam

28. diagnosis stroke akut. Semarang: Badan Penerbit Universitas Diponegoro; 2002.p. 1 - 2

29. Purves D, Ugustine GJ, Fitzpatrict D, Hall WC, Lamantania AS, Mcnamara JO, William SM, 2004. Neuroscience, Third Edition, USA : Sinauer Associates Publishers.

30. Patricia M. Davies (1990), Right in the Middle. Springer-Verlag Berlin Heidelberg New York London Paris Tokyo Hongkong.

31. Ropper AH, Brown RH, 2005. Principle of Neurology, Eighth Edition, NY : McGraw Hill Companies

32. Rohkamm R, 2004. Color Atlas Neurology, NY : Thieme Stuttgard.

33. Sherwood, Lauralee. 2001. Fisiologi Manusia : dari sel ke sistem, Jakarta: EGC.

34. Sugiyono, 2004, Statistik Non Parametris, untuk penelitian, Bandung : Alfabeta

35. Susanti (2008), Pengaruh penerapan Motor Re Learning Programme terhadap peningkatan keseimbangan berdiri pada pasien stroke hemiplegic. Jurnal Fisioterapi Indonusa, ISSN: 1858-4047 Vol. 8 No. 2 Oktober 2008 hal $109-126$.

36. Sue Raine, 2009, Bobath Concept ; Theory and Clinical Practice in Neurological Rehabilitation, Willey-Blackwell, United Kingdom

37. Thomson, Ann. Alison, Skiner. Joan, Piercy. 1991. Tidy's Physiotherapy. Great Britain: Butterworth-Heinemann.

38. Truslen T and Bonita R. Advance in ischaemic stroke epidemiology. In: Barne HJM,

39. Bogousslavsky J, Meldrum H, editor. Advance in neurology. vol 92. New York:

40. Lipincott Williams Wilkins; 2003.h.342-4 
Jurnal Ilmiah Pannmed (Pharmacyst, Analyst, Nurse, Nutrition, Midwivery, Environment, Dental Hygiene) Vol. 15 No. 3 September - Desember 2020

41. White, SJ. 2008. USMLE Raod Map Neuroscience. 2Sc. Ed. New York: McGraw Hill companies 